\title{
U.S. FLUE-CURED TOBACCO INDUSTRY COMPUTER SIMULATION OF ALTERNATIVE MARKETING SYSTEMS
}

\author{
Darrell W. Donahue \\ Robert S. Sowell \\ Neal M. Bengtson \\ North Carolina State University \\ P.O. Box 7102 \\ Raleigh, North Carolina 27695-7102 U.S.A.
}

\begin{abstract}
A preliminary study of the current U.S. flue-cured tobacco marketing system was performed to determine the need for a new system. Computer simulation models of thirteen alternative handling and marketing methods were developed. The throughput, pounds of tobacco processed in a 40 hour period, was measured. Maximum throughput predicted by the thirteen models varied from 42,933 to $2,971,311$ pounds per 40 hour period.

Design of experiments was used to select a fractional factorial design which allowed determining significant model factors. Statistical models were employed to isolate important factors and differences between alternative marketing systems. Two marketing systems are recommended to the U.S. fluecured tobacco industry for further study and analysis.
\end{abstract}

\section{INTRODUCTION}

Flue-cured tobacco is a major agricultural commodity in the southeastern U.S., especially in North Carolina where it represents approximately 20 percent of the farm gate sales and contributes approximately 7 billion dollars annually to the economy. Because of increased foreign competition it is essential that the U.S. explore all possible means of reducing its cost of producing and marketing tobacco if it is to remain competitive on the world market. Preliminary studies of the system used for marketing U.S. flue-cured tobacco suggest that the out-of-date equipment and methods being used lead to many inefficiencies in the system. This study investigates alternative tobacco marketing systems in an effort to identify lower cost systems.

\section{BACKGROUND}

In the U.S. flue-cured tobacco leaves are harvested in the field, put in boxes or hung on racks in barns for curing. After curing, they are removed from the barns and packaged into burlap sheets in 250 and 300 pound lots. The sheets are then transported to a warehouse for marketing.

At the warehouse the sheets are unloaded onto conveyors and moved to a weigh station where the weight and other accounting information are collected. The tobacco is then moved to the warehouse floor where it is positioned in rows in preparation for sale. It is sold in an ascending bid auction with the purchasers walking past tobacco. Once sold the tobacco is tagged and moved to another location to await loadout and transport to the purchaser's processing facility.

\section{SIMULATION MODEL DEVELOPMENT}

The term market center is proposed as distinct from the current tobacco auction warehouse. Simulation models are developed to describe alternative proposed market centers. Thirteen different proposed models were studied using discrete-event computer simulation techniques. Generic unloading, selling and load-out routines were developed and more detailed models of unloading, selling and load out were developed using these generic routines. The simulation models were developed using FORTRAN and SLAM II. Throughput, pounds of tobacco processed per 40 hour period, from each of these models is evaluated.

The primary routines of the models accommodate the unitizing (forming of sales package) of tobacco at the market center. This allows the producer to bring the tobacco to market in bulk form, eliminating the need for on-farm labor to prepare the tobacco for market and, consequently, reducing producer market 
preparation costs. Packaging the tobacco for sale at the market center should also reduce the amount of foreign matter in the tobacco package.

There are four main models, with several variations of each, resulting in the set of twelve models depicting alternative marketing systems. A thirteenth model was developed based on a concept similar to one often used in the marketing of fresh produce.

\section{COMPUTER SIMULATIONS}

The thirteen models described above were developed and verified. After the models were verified a set of experiments was designed to evaluate them. There are several factors that affect model performance. Factors for the first twelve model are; amount of tobacco on trucks, interarrival times of trucks, unload rate, grading rate, selling rate, load out rate, unitizing rate, and floor set up rate. Factors unique to the thirteenth model are; weigh/grade on truck, travel to grandstand area, travel through grand-stand sales area, travel to load out area, travel to reweigh area, and reweigh (tare weight).

Industry experts were asked to provide maximum and minimum data points for each of the factors that affect the output of the simulation models. These two data points represent data about which no distribution information is known. It is assumed that these data come from skewed distributions. A natural logarithm transformation was performed to find the mode point for each pair of data points. The maximum, minimum, and mode points provide the basis around which the experimental design is built.

A one-half fraction factorial design was used in all the models. In a one-half fractional factorial design confounding of higher order interactions with lower order interactions occurs. It was assumed that interactions above the fourth level contribute little to the confounding effect.

\section{MODEL THROUGHPUT}

After the models were developed and the code verified, simulation runs were made using input patterns determined by the one-half fractional factorial design. For each analysis one observation, the marketing system throughput (pounds processed per 40 hour period) was computed.

The model throughput vary from model to model and within model, largely because of the use of the fractional factorial design. The maximum model throughput is an important global element of the models because it directly affects market center profitability and marketing cost reductions for the entire industry. Since higher throughput translates to higher market center profitability, it is assumed that operators would attempt to operate a marketing system modeled by these simulations at the highest throughput possible.

The maximum model throughput range from a low of 658,239 to a high of $2,971,311$ pounds per 40 hour period. Some models experienced a limiting process (bottleneck) because of either model design or model components. The throughput from these models is significantly lower than for models where there is no bottleneck operation.

Two models exhibit throughput levels that are in the range that should be of interest to the U.S. fluecured tobacco industry. The average warehouse in the current marketing system handles roughly 325,000 pounds of tobacco per 40 hour period. In order for any alternative system to be considered practical as a replacement for the current system, it should be able to process at least $1,000,000$ pounds per 40 hour period.

\section{SUMMARY AND CONCLUSIONS}

Thirteen computer simulation models, describing alternative methods to handle the handling and marketing of U.S. flue-cured tobacco, were developed. The experiments that were designed for these models were set as factor screening runs. A factorial design was used to determine each model's response to a set of factors. Reasonable endpoints for each factor were defined with the help of tobacco industry personnel.

Model throughput, pounds of tobacco processed per 40 hour period, was the measure of system performance. It varied from a low of 42,993 pounds to a high of $2,971,311$ pounds. Some of this variation was explained by use of the factorial design experiments. Maximum throughput varied between 658,239 to $2,971,311$ pounds.

Two models, represent the best alternatives, based on throughput analysis, to the present system of marketing U.S. flue-cured tobacco. A study of the engineering economics and the economic potential of the marketing systems modeled here was conducted and is reported in another manuscript.

Results of these simulations have identified alternative marketing systems that should be further considered by the U. S. flue-cured tobacco industry. 